\title{
Evaluation of the Efficacy and Safety of Topical and Oral Glutathione in Treatment of Melasma
}

\author{
AL-SHAIMAA A. FARAHAT, M.Sc.*; LAMIA H. EL-GARHY, M.D.*; NAGEH A. EL-MAHDY, M.D.** and \\ BASMA M. ALI, M.D.* \\ The Departments of Dermatology \& Venereology, Faculty of Medicine* and Pharmacology, Faculty of Pharmacy**, Tanta University, \\ Tanta, Egypt
}

\begin{abstract}
Background: Melasma is an acquired symmetrical hyperpigmentation that typically presents on the face. Its etiology is multifactorial; its treatment remains a challenge and unsatisfactory. Glutathione is a major antioxidant which plays critical roles in protecting cells from oxidative damage and the toxicity of xenobiotic electrophiles, and maintaining redox homeostasis.
\end{abstract}

Aim of the Work: To assess the efficacy and safety of topical and oral glutathione in the treatment of melasma.

Patients and Methods: This study included 30 female patients with melasma were selected among those attending the Outpatient Clinic of Dermatology and Venereology Department, Tanta University Hospitals during the period between December, 2015 and February, 2017. The studied patients were divided into 3 groups. Group I (10 patients) applied glutathione $(2 \%)$ cream to right side of the face while placebo cream to left side (as a control) twice daily for 10 weeks. Group II (10 patients) received oral glutathione capsules $(500 \mathrm{mg} /$ day $)$ for 4 weeks. Group III (10 patients) received oral placebo capsules (as a control) once daily for 4 weeks. Modified melasma area and severity index (MASI) score was calculated before and after therapy. The patients were followed up for a period of 3 months.

Results: Significant reduction in modified MASI was observed in patients treated with topical and oral glutathione $(p=0.011)$ and $(p=0.007)$ respectively, while patients treated with topical or oral placebo had no response. Topical and oral forms of glutathione were safe and well tolerated.

Conclusion: Glutathione is safe, tolerable and effective whitening agent when used in topical cream $(2 \%)$ and also in oral form in treatment of melasma.

Key Words: Melasma - Glutathione-Modified melasma area - Severity index score.

Correspondence to: Dr. Lamia H. El-Garhy, E-Mail: lamia_elgarhy@yahoo.com.

\section{Introduction}

MELASMA is a common disorder of cutaneous hyperpigmentation $[\mathbf{1 , 2}]$. It leads to cosmetic and psychological problems to many people, especially women and can result in the early appearance of facial aging [3,4]. Melasma affects all racial groups but common among those living in areas of intense ultraviolet radiation $[\mathbf{1 , 5}$. Fitzpatrick skin phototypes III and IV were most commonly affected [6] but all skin phototypes can develop melasma [7] .

Melasma is classified into three main types: epidermal, dermal, and mixed. The epidermal type is the most common in which melanin is distributed throughout the epidermis. In the dermal type, the pigmentation due to plenty of melanophages in the dermis. In the mixed type, the pigmentation is due to increased epidermal melanin as well as dermal melanophages [8]

The exact underlying etiology of melasma remains a mystery and several well known risk factors exist $[9,10]$. Genetic predisposition is suggested by a high reported incidence in family members in several studies and it has been reported in identical twins without affecting other siblings [11]. Ultraviolet radiation (ultraviolet A and ultraviolet B), sunlight, and also visible light exposure are some of the most important factors in the development and aggravation of melasma [12]. Ultraviolet radiation induces melanocyte proliferation, migration, and melanogenesis by producing several keratinocyte-derived factors such as nitric oxide, endothelin1 , basic fibroblast growth factor, granulocyte/ macrophage colony-stimulating factor and amelanocyte-stimulating hormone $[\mathbf{1 3 , 1 4 ]}$. High estrogen and progesterone levels have been implicated in causing melasma, based on the frequent 
association of melasma with pregnancy, use of oral contraceptives and hormonal replacement therapy in postmenopausal women [15]. Drug-induced skin pigmentation accounts for $10-20 \%$ of all cases of acquired hyperpigmentation. The main ones implicated include non-steroidal anti-inflammatory drugs, phenytoin, griseofulvin, antimalarials, amiodarone, antipsychotic drugs, cytotoxic drugs and tetracyclines $[16,17]$. Cosmetics made of poorly refined ingredients containing irritating or photosensitizing substances (e.g., oil of bergamot) may have a role in developing melasma [18]. Some patients reported melasma development or worsening after stressful events [9]. Most of the cases in men and up to one-third of melasma in women are idiopathic [15].

Several therapeutic modalities are being used to treat melasma, which include numerous topical agents, chemical peels, dermabrasion, and a variety of lasers and light-based devices. However, most treatment options had been disappointing with relatively frequent failures. So, there is need for better, tolerated and effective skin lightening [19]

Glutathione is a tripeptide of three amino acids: glutamate, cysteine, and glycine [20]. Glutathione is a protein which is naturally produced in the body and has three essential crucial protective functions: as an antioxidant, booster of immune system, and a detoxifier. It decreases wrinkles, dark spots, and nourishes the skin while efficiently detoxifying the body [21]. Glutathione inhibits tyrosinase enzyme, participate in the conversion of dopaquinone to pheomelanin and quenching of reactive oxygen species and free radicals that influence tyrosinase activation [22]

In this study, we set out to assess the efficacy, tolerability and safety of oral and topical glutathione in management of melasma.

\section{Patients and Methods}

After approval of the research ethics committee (approval code 30557/10/15), this study included 30 female patients with melasma aged between 25 to 50 years old. Pregnant or lactating patients, patients with other dermatological diseases in the face, patients with history of using of any depigmenting agent (oral or local) in the last 6 months before the study, or patients suffer from systemic diseases that may cause facial hyperpigmentation were excluded from the study.

The studied patients were classified into three groups regarding line of treatment. Group I included ten patients were treated with local glutathione (2\%) cream was applied to the right side of the face and placebo cream (contain cream base only without glutathione) was applied to the left side (as a control) after cleaning melasma area with soap and water then applying it twice daily (at day and night) for 10 weeks. Group II included ten patients were treated with oral glutathione capsules $(500 \mathrm{mg} /$ day) for 4 weeks. Group III included ten patients were treated with oral placebo capsules once daily for 4 weeks as a control group. The capsules contain dextrose 5\% and were packed in identical containers.

After signing informed consents, the studied patients were subjected to detailed history taking, thorough general and dermatological examination which includes: Determining skin type of the patients according to Fitzpatrick skin types [8]. The clinical patterns of melasma [8] (The centrofacial pattern, malar pattern, mandibular pattern and extra-facial melasma). Wood's light assessment (Wood's light used was Waldmann DHLL404 M) was done and the patients were classified into: Epidermal type, dermal type, and mixed type [8] Dermoscopic examination (The dermoscope used was Dermlite II PRO HR (3 Gen, USA) was performed showing pigmentation( brown or grayish blue) which are indicators of the location of pigment within the skin [23] and structure (network, dots/ granules, and globules which represent focal accumulations of melanin in melanocytes or melanophages [23]. Scoring of the patients at baseline, at the end of treatment and at the end of the followup period ( 3 months) with modified MASI score. Modified MASI score $=0.3$ A (f) D (f) + 0.3 A (lm) $\mathrm{D}(\mathrm{lm})+0.3 \mathrm{~A}(\mathrm{rm}) \mathrm{D}(\mathrm{rm})+0.1 \mathrm{~A}(\mathrm{c}) \mathrm{D}(\mathrm{c})$.

(A) area of involvement and (D) darkness, with the (f) forehead, right malar region ( $\mathrm{rm}$ ), left mala $\mathrm{r}$ region $(\mathrm{lm})$ and chin (c), corresponding to $30 \%$, $30 \%, 30 \%$ and $10 \%$ of the total face, respectively. The area of involvement in each of these 4 areas is given a numeric value of 0 to $6(0=$ no involvement; $1=<10 \% ; 2=10 \%-29 \% ; 3=30 \%-49 \%$; $4=$ $50 \%-69 \% ; 5=70 \%-89 \%$ and $6=90 \%-100 \%)$. Darkness is rated on a scale from 0 to $4(0=$ absent; $1=$ slight; $2=$ mild; $3=$ marked and $4=$ maximum). It is calculated by multiplied the value of the area of involvement by the severity rating for darkness, for each of the 4 facial areas. The range of the total score is 0 to 24 [24].

For the patients of group I, who applied topical glutathione cream to the right side of the face, modified MASI score was calculated to this side 
separate from the left side of the face of the same patient.

Modified MASI score to the each side of the face only=0.15 A (f) D (f)+0.15 A (rm) D (rm)+ $0.05 \mathrm{~A}(\mathrm{c}) \mathrm{D}(\mathrm{c})$.

The range of the modified MASI score for one side of the face was (0-12). No response, no changes in modified MASI score at the end of therapy; poor response, less than $25 \%$ fall in modified MASI score; good response, $25-50 \%$ fall in modified MASI score; very good response, $50-75 \%$ fall in modified MASI score; and excellent response, more than $75 \%$ fall in modified MASI score.

\section{Post treatment care:}

All the patients were instructed to apply sunscreen preparations with (SPF 30) or more when going outdoors at day time. All the patients were instructed to avoid use of any other melasma therapy during the treatment. Any complaint or skin changes, whether observed by investigator or the patient as (skin dryness, erythema, irritation, burning sensation, and itching) or (flatulence, gastric irritation and allergic reaction) were reported. All patients were followed-up for a period of three months after treatment to evaluate recurrence of melasma.

Statistical analysis was done with SPSS version 20 (Armonk, NY: IBM Corp). Qualitative data were described using number and percent. The Kolmogorov-Smirnov test was used to verify the normality of distribution. Quantitative data were described using range (minimum and maximum), mean, standard deviation and median. Significance of the obtained results was judged at the 5\% level.

\section{Results}

The study comprised 30 patients with melasma diagnosed by the typical clinical appearance. Patients' demographic data was discussed in (Table 1). There was no statistically significant difference between the studied groups according to age of the patients ( $p=0.599)$; melasma duration $(p=0.502)$; clinical pattern of melasma $(p=0.879)$; Fitzpatrick skin type ( $p=0.895)$ or type of disease $(p=0.640)$.

There was statistically significant decrease in modified MASI score after therapy than before therapy in patients applied topical glutathione to right side of the face (group I) $(p=0.011)$ and in patients received oral glutathione (group II) $(p=0.007)$. There was no statistically significant difference in modified MASI score after therapy than before therapy in patients applied topical placebo cream to left side of the face (group I) and in patients received oral placebo capsules (group III) (Table 2).

There was statistically significant more clinical efficacy in lesions treated with topical glutathione to right side of face (group I) than topical placebo to left side of the face (group I) $(p=0.012)$, and there was statistically significant more clinical efficacy in lesions treated with oral glutathione (group II) than oral placebo (group III) $(p<0.001)$. There was statistically significant more clinical efficacy in lesions treated with oral glutathione (group II) than topical glutathione to right side of face (group I) $(p=0.019)$ (Table 3$)$ and (Figs. 1-4).

There was statistically significant more clinical efficacy to glutathione therapy in patients aged $\leqslant 40$ years old than those aged $>40$ years old $(p<0.001)$; in patients with melasma duration $<5$ years than those with melasma duration $>5$ years $(p=0.004)$; in patients with Fitzpatrick skin type III than those with skin type IV $(p<0.001)$; in both centrofacial and malar pattern $(p=0.003)$ and $(p=0.018)$ respectively but there was more clinical efficacy to glutathione therapy in patients with centrofacial pattern than those with malar pattern and in epidermal than in mixed and dermal types $(p<0.001)$. There was a negative correlation between the clinical efficacy of glutathione therapy and age of the patients but it was of no statical significance (Group I: $p=0.143$; Group II $p=0.403$ ) (Fig. 5). There was significant negative correlation between the clinical efficacy of glutathione therapy and melasma duration in group II ( $p=0.031)$ (Fig. 6). There was significant negative correlation between the clinical efficacy of glutathione therapy and Fitzpatrick skin type in group I ( $p=0.036)$ (Fig. 7).

Regarding tolerability and post-treatment complaints one patient only (10\%) in group I (right side of the face) experienced mild dryness which resolved by using bland emollient. No any other reported side effects. In group I (right side), recurrence was recorded in 3 patients after 3 months (all were $<40$ years old and with melasma duration $<5$ years; one was with skin type IV and 2 were with skin type III and all were with epidermal type of melasma). In group II, recurrence was recorded in 3 patients after 3 months (all were $<40$ years old; 2 were with melasma duration $<5$ years and one was with melasma duration $>5$ years; one was with skin type IV and 2 were with skin type III and one patient was with epidermal type of melasma, one was with mixed type and one was with dermal type). 
Table (1): Patients' demographic data.

\begin{tabular}{|c|c|c|c|c|c|}
\hline & \multicolumn{3}{|c|}{ Groups $[\mathrm{N}(\%)]$} & \multirow{2}{*}{$X^{2}$} & \multirow{2}{*}{$p$-value } \\
\hline & $\mathrm{I}(\mathrm{n}=10)$ & II $(n=10)$ & III $(n=10)$ & & \\
\hline \multicolumn{6}{|l|}{ Age (years): } \\
\hline$\leq 40$ & $7(70 \%)$ & $8(80 \%)$ & $6(60 \%)$ & 1.009 & 0.599 \\
\hline$>40$ & $3(30 \%)$ & $2(20 \%)$ & $4(40 \%)$ & & \\
\hline \multicolumn{6}{|l|}{ Duration of melasma (years): } \\
\hline$<1$ & $1(10 \%)$ & $0(0.0 \%)$ & $0(0.0 \%)$ & 3.689 & 0.502 \\
\hline $1-5$ & $5(50 \%)$ & $7(70 \%)$ & $4(40 \%)$ & & \\
\hline$>5$ & $4(40 \%)$ & $3(30 \%)$ & $6(60 \%)$ & & \\
\hline \multicolumn{6}{|l|}{ Melasma pattern: } \\
\hline Centrofacial & $8(80)$ & $6(60)$ & $7(70)$ & 1.009 & 0.876 \\
\hline Malar & $2(20)$ & $4(40)$ & $3(30)$ & & \\
\hline \multicolumn{6}{|l|}{ Skin type: } \\
\hline III & $5(50)$ & $6(60)$ & $7(70)$ & 0.895 & 0.895 \\
\hline IV & $5(50)$ & $4(40)$ & $3(30)$ & & \\
\hline \multicolumn{6}{|l|}{ Melasma type: } \\
\hline Epidermal & $7(70)$ & $6(60)$ & $8(80)$ & 3.135 & 0.640 \\
\hline Mixed & $3(30)$ & $2(20)$ & $1(10)$ & & \\
\hline Dermal & $0(0)$ & $2(20)$ & $1(10)$ & & \\
\hline \multicolumn{6}{|l|}{ Dermoscope finding: } \\
\hline \multicolumn{6}{|l|}{ A- Color: } \\
\hline Brown & $7(70)$ & $6(60)$ & $8(80)$ & 3.135 & 0.640 \\
\hline Brown+grayish blue & $3(30)$ & $2(20)$ & $1(10)$ & & \\
\hline Grayish blue & $0(0)$ & $2(20)$ & $1(10)$ & & \\
\hline \multicolumn{6}{|l|}{ B-Structure: } \\
\hline Network & $10(100)$ & $8(80)$ & $10(100)$ & 2.909 & 0.312 \\
\hline Dots & $4(40)$ & $1(10)$ & $0(0.0)$ & 5.201 & 0.091 \\
\hline Globules & $1(10)$ & $3(30)$ & $4(40)$ & 2.372 & 0.454 \\
\hline
\end{tabular}

Table (2): Comparison between the studied groups according to modified MASI score.

\begin{tabular}{lllll}
\hline \multirow{2}{*}{$\begin{array}{l}\text { Modified } \\
\text { MASI score }\end{array}$} & $\begin{array}{c}\text { Glutathione 2\% cream } \\
\text { (right side) }\end{array}$ & $\begin{array}{c}\text { Placebo cream } \\
\text { (left side) }\end{array}$ & $\begin{array}{c}\text { Groups II } \\
(\mathrm{n}=10)\end{array}$ & $\begin{array}{c}\text { Groups III } \\
(\mathrm{n}=10)\end{array}$ \\
\cline { 2 - 3 } $\begin{array}{llll}\text { Before: } \\
\text { Min.-Max. }\end{array}$ & $2.10-5.60$ & $1.05-5.60$ & $3.0-12.0$ & $1.05-10.0$ \\
Mean \pm SD. & $4.22 \pm 1.45$ & $3.41 \pm 1.63$ & $5.98 \pm 2.98$ & $3.87 \pm 2.49$ \\
Median & 4.68 & 3.30 & 5.15 & 3.20 \\
After: & & & & \\
Min.-Max. & $1.50-5.60$ & $1.05-5.60$ & $1.80-6.90$ & $1.05-10.0$ \\
Mean \pm SD. & $3.61 \pm 1.38$ & $3.41 \pm 1.63$ & $3.64 \pm 1.96$ & $3.87 \pm 2.49$ \\
Median & 3.40 & 3.30 & 2.70 & 3.20 \\
$p$ & $0.011 *$ & 1.000 & $0.007 *$ & 1.000 \\
\hline
\end{tabular}

$p$ : $p$-value for Wilcoxon signed ranks test for comparing between before and after in each group. *: Statistically significant at $p \leq 0.05$. 
Table (3): Comparison between the studied groups according to clinical efficacy of therapy.

\begin{tabular}{|c|c|c|c|c|c|c|c|c|}
\hline \multirow{3}{*}{$\begin{array}{l}\text { Clinical } \\
\text { efficacy }\end{array}$} & \multicolumn{4}{|c|}{ Groups $I(n=10)$} & & & & \\
\hline & \multicolumn{2}{|c|}{$\begin{array}{c}\text { Glutathione } 2 \% \text { cream } \\
\text { (right side) }\end{array}$} & \multicolumn{2}{|c|}{$\begin{array}{l}\text { Placebo cream } \\
\quad \text { (left side) }\end{array}$} & \multicolumn{2}{|c|}{$\begin{array}{c}\text { Groups II } \\
(\mathrm{n}=10)\end{array}$} & \multicolumn{2}{|c|}{$\begin{array}{l}\text { Groups III } \\
(\mathrm{n}=10)\end{array}$} \\
\hline & No. & $\%$ & No. & $\%$ & No. & $\%$ & No. & $\%$ \\
\hline No response & 2 & 20.0 & 10 & 100.0 & 1 & 10.0 & 10 & 100.0 \\
\hline Poor response & 5 & 50.0 & 0 & 0.0 & 2 & 20.0 & 0 & 0.0 \\
\hline Good response & 3 & 30.0 & 0 & 0.0 & 4 & 40.0 & 0 & 0.0 \\
\hline Very good response & 0 & 0.0 & 0 & 0.0 & 3 & 30.0 & 0 & 0.0 \\
\hline Min.-Max. & \multicolumn{2}{|c|}{$0.0-44.55$} & \multicolumn{2}{|c|}{$0.0-0.0$} & \multicolumn{2}{|c|}{$0.0-62.30$} & \multicolumn{2}{|c|}{$0.0-0.0$} \\
\hline Mean \pm SD. & \multicolumn{2}{|c|}{$13.62 \pm 15.63$} & \multicolumn{2}{|c|}{$0.0 \pm 0.0$} & \multicolumn{2}{|c|}{$37.05 \pm 19.43$} & \multicolumn{2}{|c|}{$0.0 \pm 0.0$} \\
\hline Median & & & & 0 & & & & 0 \\
\hline Sig. bet. Grps & \multicolumn{8}{|c|}{$p_{1}=0.012^{*}, p_{2}=0.019^{*}, p_{3}<0.001 *$} \\
\hline
\end{tabular}

p1: $p$-value for Wilcoxon signed ranks test for comparing between glutathione $2 \%$ cream (right side) and placebo without glutathione (left side)

p2: $p$-value for Mann Whitney test for comparing between glutathione 2\% cream (right side) and group II. 33: $p$-value for Mann Whitney test for comparing between group II and III.

* : Statistically significant at $p \leq 0.05$.

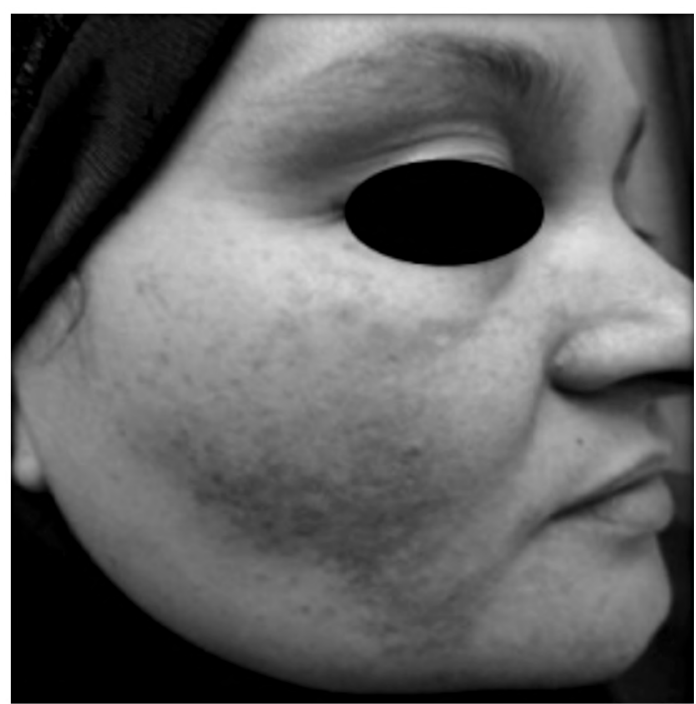

Fig. (1A): Female patient with epidermal melasma before treatment.

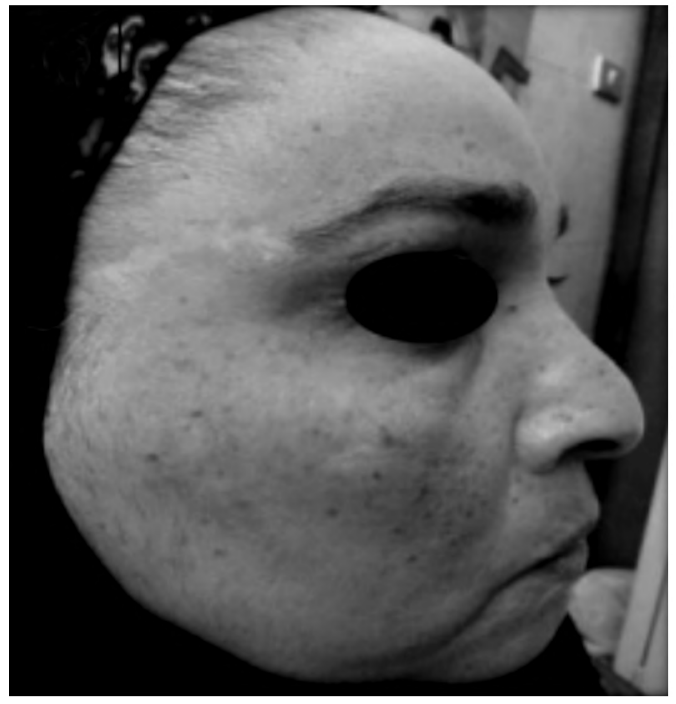

Fig. (2A): Female patient with mixed melasma before treatment.

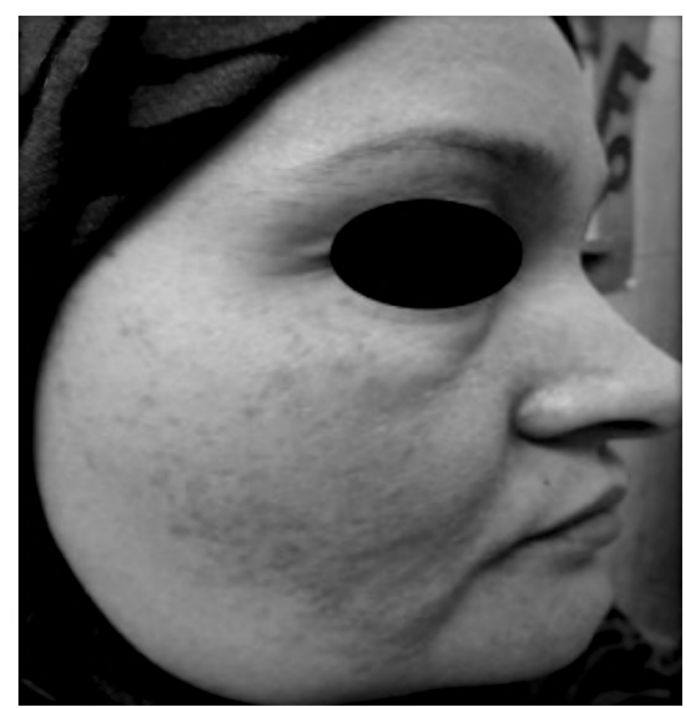

Fig. (1B): Good improvement after treatment with topical glutathione cream.

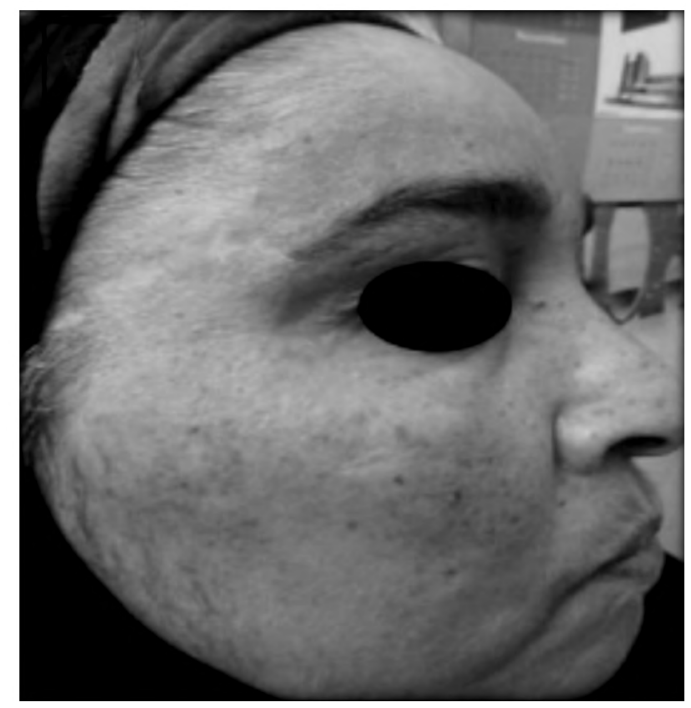

Fig. (2B): Poor improvement after treatment with topical glutathione cream. 


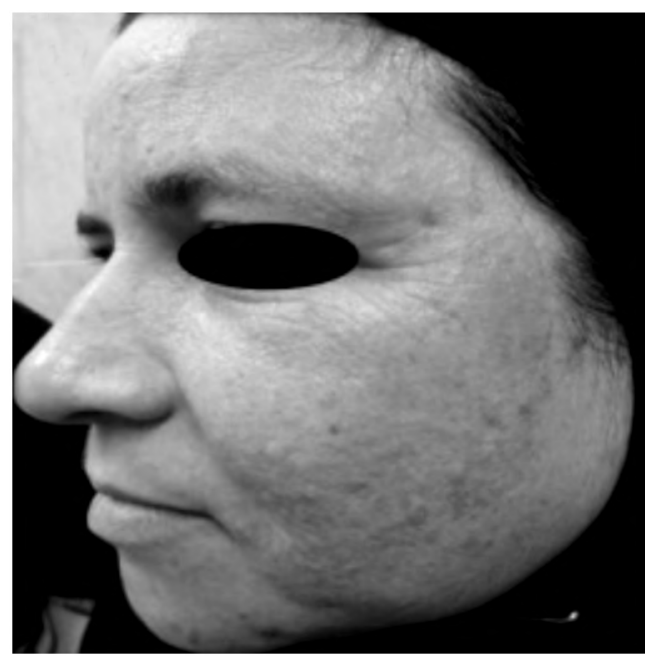

Fig. (3A):Female patient with epidermal melasma before treatment.

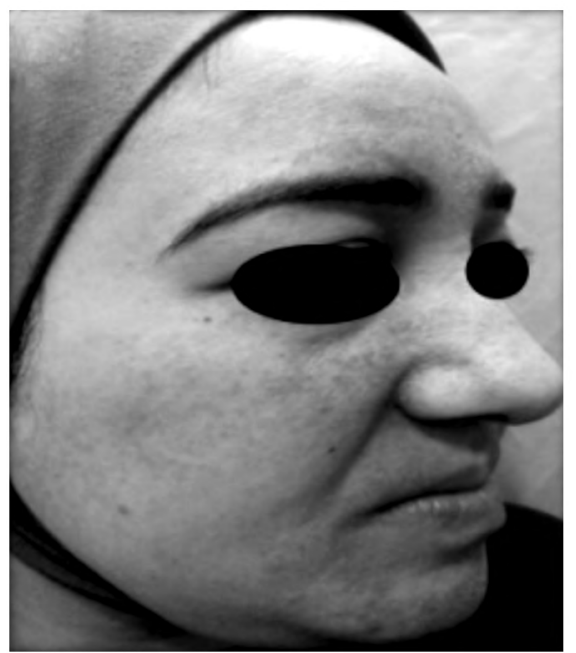

Fig. (4A): Female patient with dermal melasma before treatment.

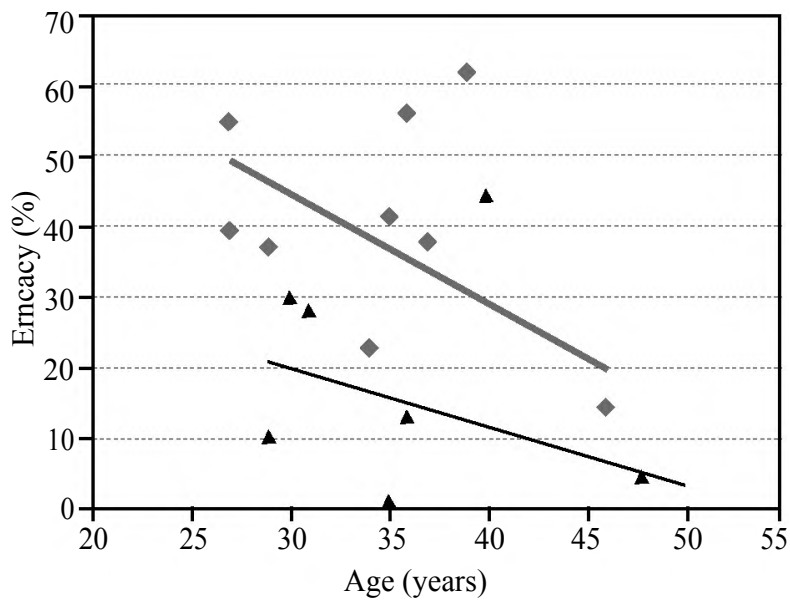

$\Delta$ Groups I ( $\mathrm{rs}=-0.498, p=0.143)$

$\diamond$ Groups II ( $\mathrm{rs}=-0.298, \mathrm{p}=0.403)$

Fig. (5): Correlation between the clinical efficacy of glutathione therapy and the age of the studied patients.

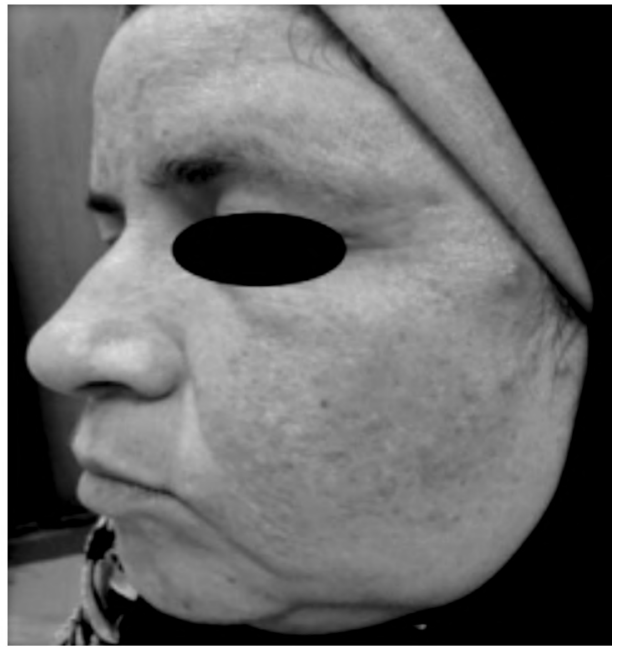

Fig. (3B): Very good improvement after treatment with oral glutathione.

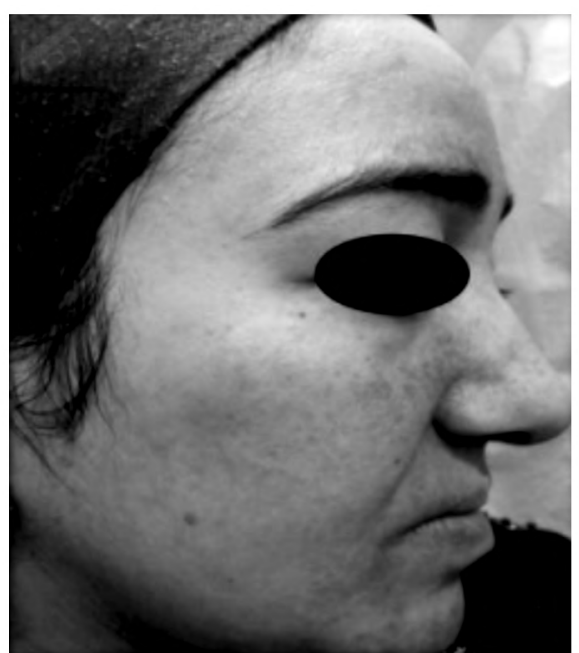

Fig. (4B): Poor improvement after treatment with oral glutathione.

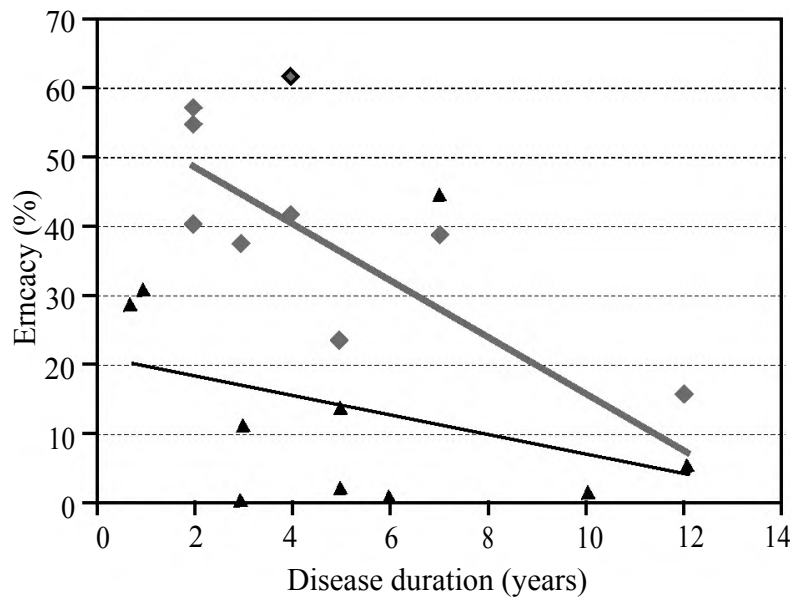

$\Delta$ Groups I ( $\mathrm{rs}=-0.272, p=0.447)$

$\triangle$ Groups II ( $\left(\mathrm{ss}=-0.679^{*}, p=0.031^{*}\right)$

Fig. (6): Correlation between the clinical efficacy of glutathione therapy and melasma duration. 


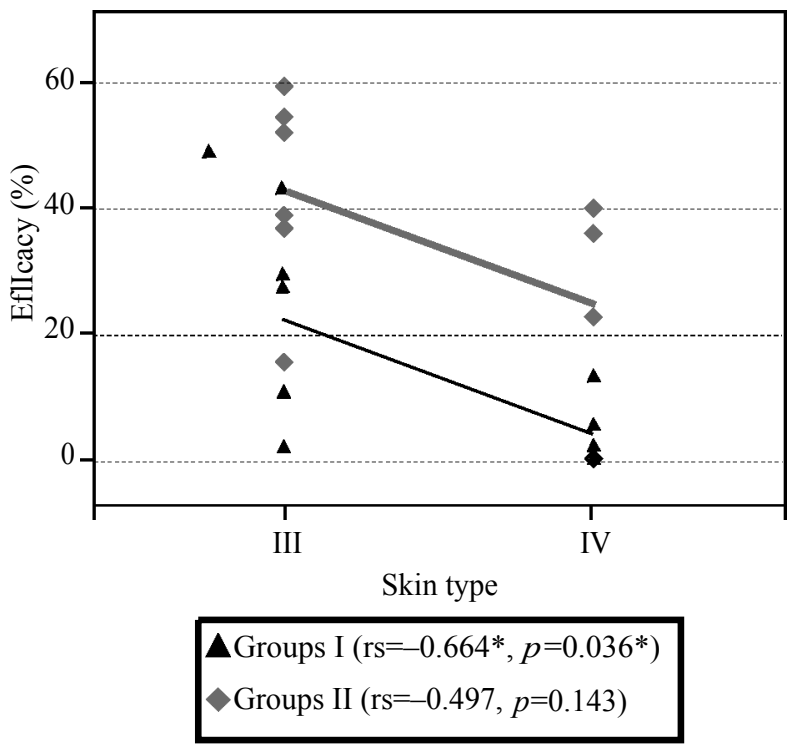

Fig. (7): Correlation between the clinical efficacy of glutathione therapy and Fitzpatrick skin type.

\section{Discussion}

Melasma is an acquired disorder of symmetrical hyperpigmentation. Appearing as light brown to dark patches on the forehead, malar areas, nose, and chin [25]. Melasma has traditionally been treated with a combination of photoprotection, avoidance of trigger factors, and topical depigmenting agents with varying degrees of success [26] Glutathione has been recognized as a master antioxidant. It is involved in many important biological processes such as deoxyribonucleic acid and protein synthesis and the protection of cells through the metabolism of xenobiotics and carcinogens. It also functions to detoxify electrophilic compounds and acts as a reductant in the detoxification of peroxides, protecting cells from intracellular free radicals and reactive oxygen species [27]

In this study, the patients who were treated with topical glutathione showed significant decrease in modified MASI score from base line to the end of treatment than who used topical placebo. These results were in consistent with Watanabe et al., [20] studied skin whitening and skin condition improving effects of topical oxidized glutathione lotion $2 \%$ to one side of the face and a placebo lotion to the other side twice daily for 10 weeks. The skin melanin index was significantly lower with treatment measured by Mexameter (a tool objectively measures melanin index of skin) than with placebo at the end of the study period. They also reported significant increases in moisture content of the stratum corneum by Corneometer, suppression of wrinkle formation, and improvement in skin smoothness by SkinSys. Sriharsha et al., [28] used glutathione soap for 3 months for melasma patients and showed that there was some improvement in the hyperpigmentation in most patients.

In the current study, the patients who were treated with oral glutathione showed significant decrease in modified MASI score from base line to the end of treatment than who used oral placebo. These results were in consistent with Arjinpathana and Asawanonda, [21] studied the effect of oral glutathione on the skin melanin index; there patients received glutathione capsules in a dose $500 \mathrm{mg}$ per day for 4 weeks and control group received placebo capsules for the same period. The melanin indices decreased consistently at all six sites measured by Mexameter in subjects who received glutathione. The reductions were statistically significantly greater than those receiving placebo at two sites, namely the right side of the face and the sunexposed left forearm. This was similarly reflected in the changes in the number of ultraviolet spots, as measured by VISIA system. Handog et al., [27] studied safety and efficacy of glutathione lozenge as a skin-lightening agent; their patients received lozenge containing $500 \mathrm{mg}$ glutathione daily for eight weeks and showed that all patients $(100 \%)$ showed a significant decrease in melanin index from baseline measured by Mexameter.

According to clinical efficacy of the therapy in this study; oral glutathione group showed the best results with median 39.23 , followed by topical glutathione group with median 8.04, while topical and oral placebo groups showed no response.

According to the response to therapy in the present study, patients who were treated with oral glutathione showed very good results in 30\%, $40 \%$ had good results, $20 \%$ had poor results and $10 \%$ showed no response. While patients who were treated with topical glutathione showed good results in $30 \%, 50 \%$ had poor results and $20 \%$ showed no response.

On comparing the results of the studied groups, oral glutathione showed statistically significant more clinical efficacy than topical glutathione cream. This may be due to that oral administration of the drug enhance and ensure steady bioavailability [29] while topical form may require frequent application, larger concentration, application for longer duration or application with other methods like dermapen to enhance transdermal delivery of drug [30]

Regarding the relation between the clinical efficacy of therapy and age of the patients in this study, there was statistically significant more clin- 
ical efficacy to glutathione therapy in patients aged $<40$ years old than those aged $>40$ years old. This may be explained by the more compliance of young patients to the therapy and the more attention to their appearance.

In the present study, there was statistically significant more clinical efficacy to glutathione therapy in patients with melasma duration $<5$ years than those with melasma duration $>5$ years. This may be explained by cumulative effect of the sun and transformation of epidermal melasma to mixed and dermal type with the long duration.

Regarding skin type in this study, there was statistically significant more clinical efficacy to glutathione therapy in patients with Fitzpatrick skin type III than those with skin type IV. This may be due to skin type IV tans easily than skin type III.

In this study, there was statistically significant more clinical efficacy to glutathione therapy in patients with epidermal type of melasma than in mixed and dermal type. This may be explained by presence of melanin in epidermal melasma in the superficial cells so easily targeted by the therapy and the presence of melanin deep in the dermis within macrophages make it difficult to be removed by the therapy.

In this study, oral glutathione was well tolerated without any reported side effects. Only few patients experienced mild skin dryness in early days after application of glutathione cream which resolved by application of emollient cream.

Arjinpathana and Asawanonda, [21] found that one patient experienced flatulence in the first few days after taking oral glutathione capsules otherwise the treatment was well tolerated. In another study by Handog et al., [27] found that few patients complained of soreness in the gums caused by use of oral glutathione and the lozenge was sour and chalky in texture.

Watanabe et al., [20] found that few patients experienced mild erythema of the face on days 2 and 3 after use of local glutathione. However, the erythema had disappeared by day 4 without the need to discontinue the application of glutathione. No adverse reactions related to GSSG were reported during the study period. All patients tolerated local GSSG lotion well. Sriharsha et al., [28] found that there was no side effect with glutathione soap in their study.
In the present study, the recurrence rate was recorded in $30 \%$ of patients who used topical glutathione after 3 months, and in $30 \%$ of patients who received oral glutathione after 3 months.

From this study, it could be concluded that glutathione is safe, inexpensive and effective whitening agent in the treatment of melasma. Both topical and oral forms of glutathione were well tolerated for all types of skin. It is better to use topical form in recent lesions, epidermal melasma type and in skin type III. It is advised to use oral form in old lesions, mixed melasma type, and skin type IV. Dermal melasma type may need combination of both topical and oral glutathione. Duration of glutathione treatment must be not less than 10 weeks in topical form and not less than 4 weeks in oral form.

\section{References}

1- BANDYOPADHYAY D.: Top ical treatment of melasma Indian J. Dermatol., 54 (4): 303-309, 2009.

2- NI Z., MU Y. and GULATI O.: Treatment of melasma with pyogenol. Phytother. Res., 16 (6): 567-571, 2002.

3- WATANABE S.: Facial Dermal Melanocytosis. Austin. J. Dermatolog., 1 (2): 6, 2014.

4- TEO W.L., GAN E., JINGHAN A., CHUAH S.Y., ALAIN K., GOH C., et al.: Double blind placebo controlled trial to evaluate of the effectiveness of a dietary supplement rich in carotenoids as adjunct to topical lightening cream for the treatment of melasma: A pilot study. Journal of Pigmentary Disorders, 2 (2): 164 -170, 2015.

5- PANDYA A.G. and GUEVARA I.L.: Disorders of hyperpigmentation. Dermatol. Clin., 18 (1): 91-98, 2000.

6- ORTONNE J.P., ARELLANO I., BERNEBURG M., CESTARI T., CHAN H., GRIMES P., et al.: A global survey of the role of ultraviolet radiation and hormonal influences in the development of melasma. J. Eur. Acad. Dermatol. Venereol., 23 (11): 1254 - 1262, 2009.

7- HEXSEL D., LACERDA D.A., CAVALCANTE A.S., CARLOS FILHO A.S., KALIL C.L., AYRES E.L., et al.: Epidemiology of melasma in Brazilian patients: a multicenter Study. Int. J. Dermatol., 53 (4): 440- 444, 2014.

8- NICOLAIDOU E. and KATSAMBAS A.D.: Pigmentation disorders: hyperpigmentation and hypopigmentation. Clin. Dermatol., 32 (1): 66-72, 2014.

9- TAMEGA A.D., MIOT L.D., BONFIETTI C., GIGE T.C., MARQUES M.E. and MIOT H.A.: Clinical patterns and epidemiological characteristics of facial melasma in Brazilian women. J. Eur. Acad. Dermatol. Venereol., 27 (2): 151-156, 2013.

10- GUINOT C., CHEFFAI S., LATREILLE J., DHAOUI M.A., YOUSSEF S., JABER K., et al.: Aggravating factors for melasma: a prospective study in 197 Tunisian patients. J. Eur. Acad. Dermatol. Venereol., 24 (9): 1060-1069, 2010. 
11- KANG W.H., YOON K.H., LEE E.S., KIM J., LEE K.B., YIM H., et al.: Melasma: Histopathological characteristics in 56 Korean patients. Br. J. Dermatol., 146 (2): 228-237.

12- VICTOR F.C., GELBER J. and RAO B.: Melasma: A review. J. Cutan. Med. Surg., 8 (2): 97-102, 2004.

13- COSTIN G.E. and HEARING V.J.: Human skin pigmentation: Melanocytes modulate skin color in response to stress. FASEB J., 21 (4): 976-994, 2007.

14- PÉREZ-BERNAL A., MUÑOZ-PÉREZ M.A. and CAMACHO F.: Management of facial hyperpigmentation. Am. J. Clin. Dermatol., 1 (5): 261-268, 2000.

15- ORTONNE J.P., ARELLANO I., BERNEBURG M., CESTARI T., CHAN H., GRIMES P., et al.: A global survey of the role of ultraviolet radiation and hormonal influences in the development of melasma. J. Eur. Acad. Dermatol. Venereol., 23 (11): 1254 - 1262, 2009.

16- DEREURE O.: Drug-induced skin pigmentation. Epidemiology, diagnosis and treatment. Am. J. Clin. Dermatol., 2 (4): 253-262, 2001

17- RIGOPOULOS D., GREGORIOU S. and KATSAMBAS A.: Hyperpigmentation and melasma. J. Cosmet. Dermatol., 6 (3): 195-202, 2007.

18- PRABHA N., MAHAJAN V.K., MEHTA K.S., CHAUHAN P.S. and GUPTA M.: Cosmetic contact sensitivity in patients with melasma: Results of a pilot study. Dermatol. Res. Pract., 316219-316228, 2014.

19- RODRIGUES M. and PANDYA A.G.: Melasma: Clinical diagnosis and management options. Australas J. Dermatol., 56 (3): 151-163, 2015.

20- WATANABE F., HASHIZUME E., CHAN G. and KAMIMURA A.: Skin-whitening and skin-conditionimproving effects of topical oxidized glutathione: A double-blind and placebo-controlled clinical trial in healthy women. Clin. Cosmet. Investig. Dermatol., 7: 267-274, 2014.

21- ARJINPATHANA N. and ASAWANONDA P.: Glutathione as an oral whitening agent: A randomized, double- blind, placebo controlled study. J. Dermatolog. Treat., 23 (2): 97-102, 2012.

22- VILLARAMA C.D. and MAIBACH H.I.: Glutathione as a depigmenting agent: An overview. Int. J. Cosmet. Sci., 27 (3): 147-153, 2005

23- TAYLOR S., WESTERHOF W., IM S. and LIM J.: Noninvasive techniques for the evaluation of skin color. J. Am. Acad. Dermatol., 54 (5): S282-S290, 2006.

24- PANDYA A.G., HYNAN L.S., BHORE R., RILEY F.C., GUEVARA I.L., GRIMES P., et al.: Reliability assessment and validation of the Melasma Area and Severity Index (MASI) and a new modified MASI scoring method. J. Am. Acad. Dermatol., 64 (1): 78-83, 2011.

25- LEE A.Y.: Recent progress in melasma pathogenesis. Pigment. Cell. Melanoma. Res., 28 (6): 648-660, 2015.

26- SHETH V.M. and PANDYA A.G.: Melasma: A comprehensive update: Part II. J. Am. Acad. Dermatol., 65 (4): 699-714, 2011.

27- HANDOG E.B., DATUIN M.S. and SINGZON I.A.: An open-label, single-arm trial of the safety and efficacy of a novel preparation of glutathione as a skin-lightening agent in Filipino women. Int. J. Dermatol., 55 (2): 153157,2016

28- SRIHARSHA M., ALEKHYA P., REDDY K.N., DARSINI T.P. and REDDY K.S.: Glutathione as a whitening agent in the treatment of melanosis on face. IJPPDR, 5 (1): 16, 2015 .

29- GARG B.J., SARASWAT A., BHATIA A. and KATARE O.P.: Topical treatment in vitiligo and the potential uses of new drug delivery systems. Indian. J. Dermatol. Venereol. Leprol., 76 (3): 231-328, 2010.

30- FABBROCINI G., de VITA V., FARDELLA N., PASTORE F., ANNUNZIATA M.C., MAURIELLO M.C., et al.: Skin Needling to Enhance Depigmenting Serum Penetration in the Treatment of Melasma. Plast. Surg. Int., 158241-158248, 2011. 


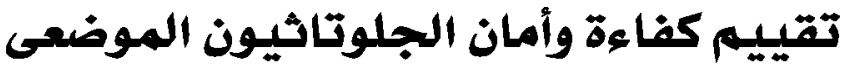

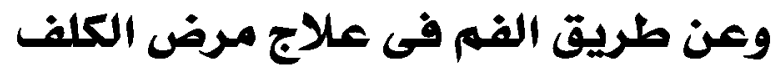

يعد الكلف من أمراض فرط التصبخ المزمنة والمتكرة التى تصيب لوجه. ويعتبر أكثر شيوعاً بين النساء وبشكل خاص بين أصحاب ألماب

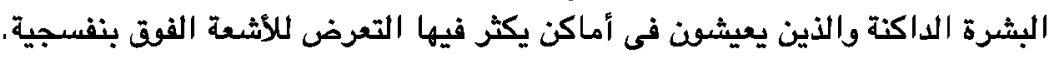
الهدف من هذه الدراسة: هو تقييم كفاءة وأمان عقارالجلوتاثيون فى علاج مرض الكلف.

أشملت هذه الدراسة على ·r مريض بالكلف كلهم من الإناث وقد تم تجميع المرضى من الميادات الخارجية لقسم الأمراض الجلدية

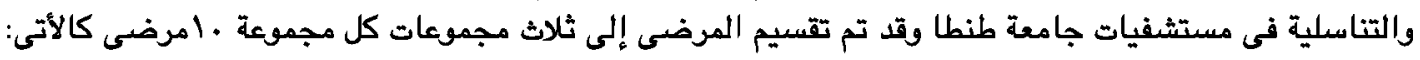

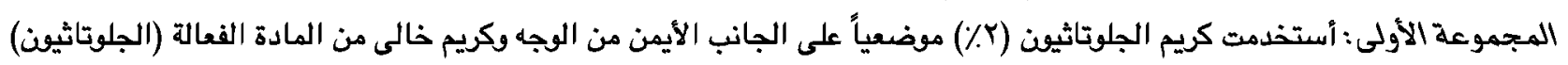

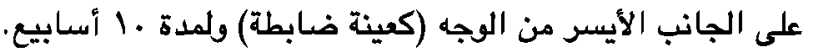

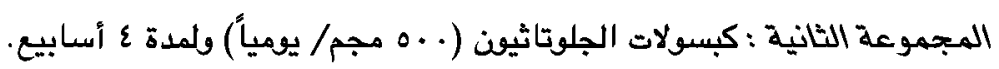

المجموعة الثالثة : كبسولات تحتوى على دكستروز 1 \% خالية من الجلوتاثيون عن طريق الفم مرة واحدة يومياً ولمدة ع ع أسابيع.

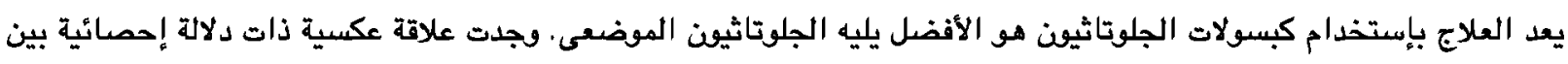

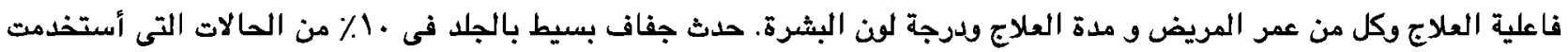

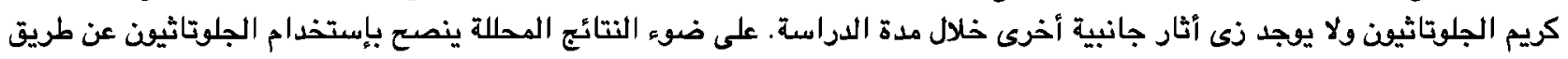

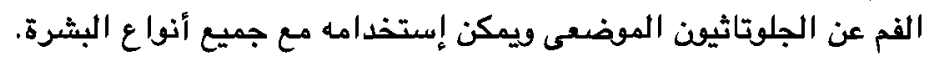
يوصى بالمزيد من الدراسات على عدد أكبر من المرضى ولمدة أطقل لدراسة قدرة الجلوتاثيون على منع عودة الكلف مرة أخرى بعد التصسن مع إستخدام تركيزات مختلفة من الجلوتئاثيون. 